\title{
Aplikasi Game 2D Petualangan Bre Skater Boy Berbasis Android
}

\author{
Sutariyani*1, Wisnu Wendanto ${ }^{2}$, Muhammad Nur Ali $^{3}$ \\ ${ }^{1,3}$ Program Studi Sistem Informasi, STMIK AUB, Surakarta, Indonesia \\ ${ }^{2}$ Program Studi Sistem Komputer, STMIK AUB, Surakarta, Indonesia \\ e-mail: *1 tari.yani@stmik-aub.ac.id, ${ }^{2}$ wisnu.wendanto@stmik-aub.ac.id, ${ }^{3}$ nurali@gmail.com
}

\begin{abstract}
Abstrak
Perkembangan teknologi informasi di era digital saat ini banyak sekali yang menggunakan dan memanfaatkan gadget guna dalam berbagai hal, seperti halnya anak-anak seringkali terjebak atau kecanduan dalam menggunakan gadget untuk bermain game dan menghabiskan banyak waktu dalam bermain game. Dari kejadian ini sangat memprihatinkan dan pengawasan orang tua sangat dibutuhkan jika kondisi tersebut berkelanjutan, hal ini bisa berdampak negative yang mempengaruhi perilaku anak-anak dari segi berkomunikasi dan menjadi kebiasaan dalam berbicara yang baik. Pada kesempatan ini peneliti membangun sebuah aplikasi game berbasis android yang diharapkan mampu memberikan hiburan dan edukasi bagi anak terutama dalam segi kebiasaan berbicara, karena sering kali anak yang gagal dalam bermain aplikasi game mereka berbicara tidak baik. Hasil penelitian ini dapat memberikan hiburan ataupun edukasi pada anak yang dapat dimainkan kapan saja dan dimanapun berada karena gadget smartpone itu sendiri lebih praktis bisa dibawa kemanapun berada.
\end{abstract}

Kata kunci: gadget, aplikasi games, anak-anak, android

\section{PENDAHULUAN}

Perkembangan teknologi informasi di era digital saat ini banyak sekali yang menggunakan dan memanfaatkan gadget guna dalam berbagai hal, seperti game, bisnis, komunikasi, dan lain-lain. Tidak lepas dari manfaat itu, anak-anak seringkali terjebak atau kecanduan dalam menggunakan gadget untuk bermain game dan menghabiskan banyak waktu dalam bermain game. Dari kejadian ini sangat memprihatinkan dan pengawasan orang tua sangat dibutuhkan jika kondisi tersebut berkelanjutan, hal ini bisa berdampak negativeyang mempengaruhi perilaku anak-anak dari segi berkomunikasi dan menjadi kebiasaan dalam berbicara yang baik.

Pada kesempatan ini peneliti mencoba membangun sebuah aplikasi game yang diharapkan mampu memberikan hiburan dan edukasi bagi anak terutama dalam segi kebiasaan berbicara, karena sering kali anak yang gagal dalam bermain aplikasi game mereka berbicara tidak baik.

Pemanfaatan aplikasi game android ini bisa memberikan hiburan ataupun edukasi pada anak yang dapat dimainkan kapan saja dan dimanapun berada karena gadget smartpone itu sendiri lebih praktis bisa dibawa kemanapun berada.

Seiring berkembangnya zaman yang mempengaruhi perkembangan teknologi game, Android merupakan salah satu sistem operasi yang mendukung aplikasi game 2D Petualangan Bre Skater Boy. Android adalah sistem operasi berbasis Linux yang dirancang untuk perangkat bergerak layar sentuh seperti smartphone dan tablet, awalnya Android dikembangkan oleh Android Inc, dengan dukungan finansial dari Google yang kemudian membelinya pada tahun 
2005. Sistem operasi ini dirilis secara resmi pada tahun 2007. (https://id.m.wikipedia.org/wiki/Android.).

Keunggulan utama Android adalah open source (terbuka), sehingga siapa saja dapat menjadi developer(pengembang) aplikasi berbasis Android. Beberapa fitur utama dari Android antara lain Multi-touch, support java, accelerometer, serta kemampuan dasar mobile phone pada umumnya, hal inilah yang mendorong penulis melakukan pengembangan game berbasis Android. Maka penulis melakukan penelitian berjudul "Aplikasi Game 2D Petualangan Bre Skater Boy Berbasis Android".

\section{METODE PENELITIAN}

\subsection{Analisis Sistem}

Analisis merupakan penguraian dari suatu sistem yang utuh ke dalam bagian-bagian komponen untuk mengidentifikasi dan mengevaluasi, sehingga di dapatkan solusinya. Dari hasil pengamatan sangat jarang sebuah aplikasi gameberbasis android yang memberikan edukasi melalui media suara. Oleh karena itu untuk mengatasi masalah tersebut maka penelitian akan merancang dan membangun sebuah aplikasi game petualangan berbasis android yang mendidik anak dalam berbicara saat memainkan game pada perangkat mobile phone berbasis android.

Pembuatan aplikasi game ini menggunakan metode sekuensi (waterfall). Metode air terjun atau sering disebut waterfall, dimana hal ini menggambarkan pendekatan yang sistematis dan juga berurutan pada pengguna lalu berlanjut melalui tahapan perencanaan (lanning), permodelan (modeling), kontruksi (contruction), dan penyerahan sistem ke setiap pengguna/pemain (deployment), yang diakhiri dengan dukungan pada perangkat lunak lengkap yang dihasilkan. Dalam metode waterfall memiliki beberapa tahapan yang berurutan. Dan tahapan - tahapan dalam metode ini adalah sebagai berikut :

1. Analisis Sistem

Analisis merupakan tahap analisa terhadap hal-hal yang diperlukan dalam pembangungan perangkat lunak.

2. Perancangan (Design)

Perancangan merupakan tahap penerjemahaan dari keperluan data atau penggambaran perangkat lunak yang akan dibangun.

3. Pengkodean (Coding)

Pada tahap ini dilakukan proses penerjemahan dari keperluan data atau pemecahan masalah yang telah dirancang ke dalam bahasa pemrograman komputer.

4. Pengujian (Testing)

Setelah prorgram selesai dibuat, maka tahap berikutnya adalah uji coba terhadap program tersebut.

5. Pemeliharaan (Maintenance)

Tahap ini merupakan tahap akhir dimana perangkat lunak yang sudah selesai dan dapat mengalami perubahan atau penambahan sesuai dengan permintaan user.

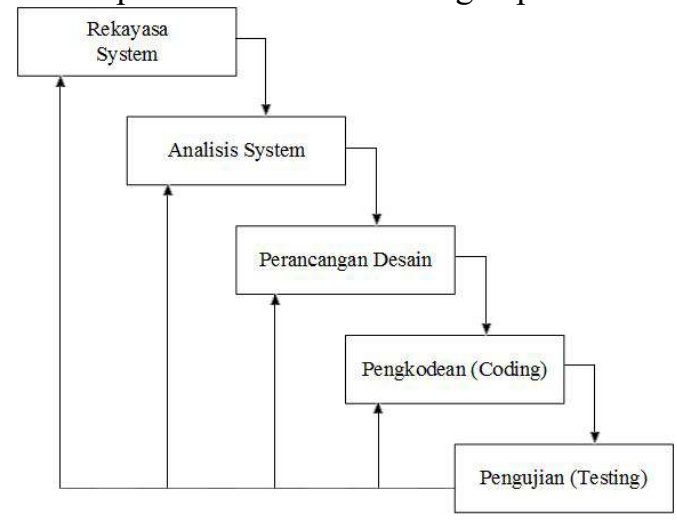

GO INFOTECH: JURNAL ILMIAH STMIK AUB Vol. 25, No. 1, Juni 2019 : 29 - 34 
Gambar 1 Metode Waterfall

\subsection{Perancangan Game}

2.2.1 Pitch (Konsep Awal)

Penulis menerapkan konsep game yang sifatnya berpetualangan, dengan mengangkat sebuah karakter dari nama Bre Skater Boy. Game ini dirancang khusus dengan tujuan sebagaisalah satu media hiburan yang mendidik anak,berkaitan dengan perilaku saat berbicara serta menjadi pilihan untuk menghilangkan kejenuhan.Game ini dimainkan oleh 1 tokoh yaitu Bre Skater Boy. Game ini menggambarkan perjalanan seorang Skater, yang melintasi sebuah kota, daerah tersebut bernama Surakarta. Skater Boy. dalam perjalanannya mempunyai misi untuk melintasi lintasan kota untuk mencapai jarak sejauh mungkin untuk mendapatkan point atau score sebanyak-banyaknya, dan harus melewati rintangan dalam perjalanan tersebut.

\subsubsection{Pre-Production}

Tahap ini menentukan kebutuhan perangkat keras dan perangkat lunak dalam building game. Selain itu juga menentukan usecase diagram, flowchart, activity diagram, class diagram, storyboard dan desain karakter dalam game.

\subsubsection{Building}

Build game adalah proses memindahkan atau menjadikan file yang dibuat di unity dijadikan game android yang memerlukan sebuah komponen SDK untuk build aplikasi game.

\subsubsection{Alpha Testing}

Untuk melakukan alpha testing pada game, penulis melakukan metode black-box testing. Pengetesan ini dilakukan untuk menentukan bahwa game tersebut sudah layak atau belum untuk digunakan serta untuk kebutuhan yang diharapkan oleh developer.

\subsubsection{Beta Testing}

Untuk melakukan beta testing pada game, penulis melakukan metode black-box testing kembali. Namun pada proses ini dilakukan oleh tim eksternal unutk mengetahui game tersebut sudah layak atau belum untuk diginakan serta memenuhi kebutuhan yang diharapkan oleh pengguna.

\subsubsection{Publishing}

Tahap ini melakukan proses mempublikasikan hasil dari beta testing yang telah diperbaiki,untuk dapat disebar luaskan pada pengguna game.

\section{HASIL DAN PEMBAHASAN}

\subsection{Hasil}

Pada bagian ini akan dijelaskan bagaimana penggunakan Aplikasi Game 2D Petualangan Bre Skater BoyBerbasis Android. Berikut Penjelasan dari fitur atau menu yang telah dibuat :

\section{Halaman Menu Utama}

Halaman menu utama merupakan halaman yang paling memuat pilihan dalam aplikasi game ini, antara lain seperti start game, credit, high score. Tampilan dapat dilihat pada gambar 2. 


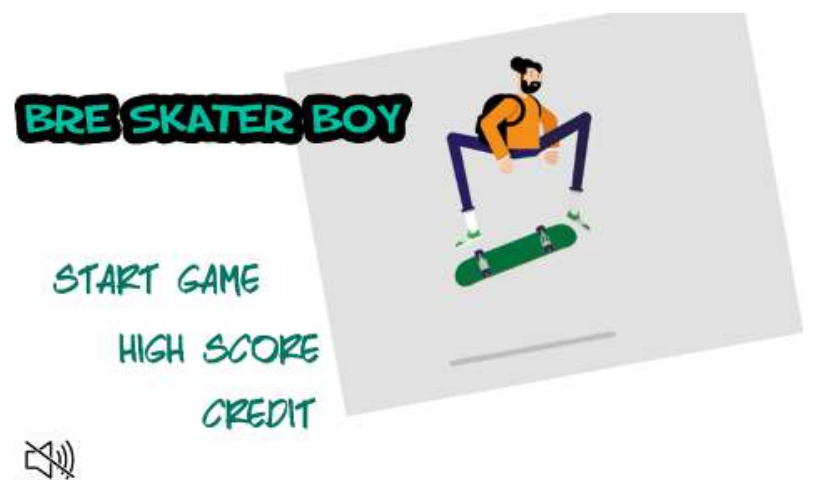

Gambar 2 Halaman Menu Utama

Pemain dapat memilih pilihan antara lain seperti : start game (untuk memulai permainan), credit (menampilkan seputar info tentang penulis atau perancang aplikasi game), high score (untuk menampilkan score paling tertinggi sampai score paling terendah).

2. Halaman Game Play

Halaman gameplay adalah tampilan halaman ketika pemain sedang memainkan aplikasi game. Berikut tampilan dapat dilihat pada gambar 3.

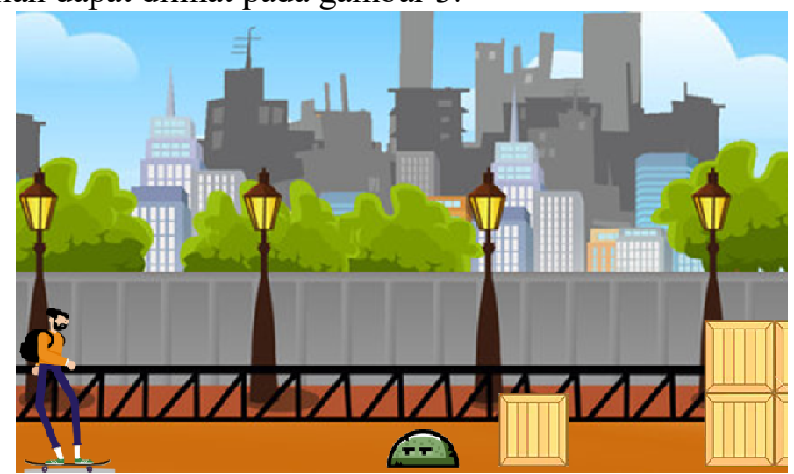

Gambar 3 Halaman Game Play

Pada gambar 3 menunjukan pemain sedang memainkan aplikasi game, dengan posisi kamera mengikuti arah pergerakan karakter dalam permainan tersebut, pemain harus melewati obstacle(rintangan) dengan menyentuh screen lalu geser kearah atas untuk melompat. Untuk melompati rintangan yang lebih tinggi harus dengan cara drag, yaitu pemain menyentuh screen dan menahanya agak lama lalu menggeser ke atas dengan posisi tangan masih menahan screen. Dalam gameplayterlihat karakter melompati rintangan lebih besar dengan lompatan lebih tinggi dari sebelumnya.

3. Halaman Game Over

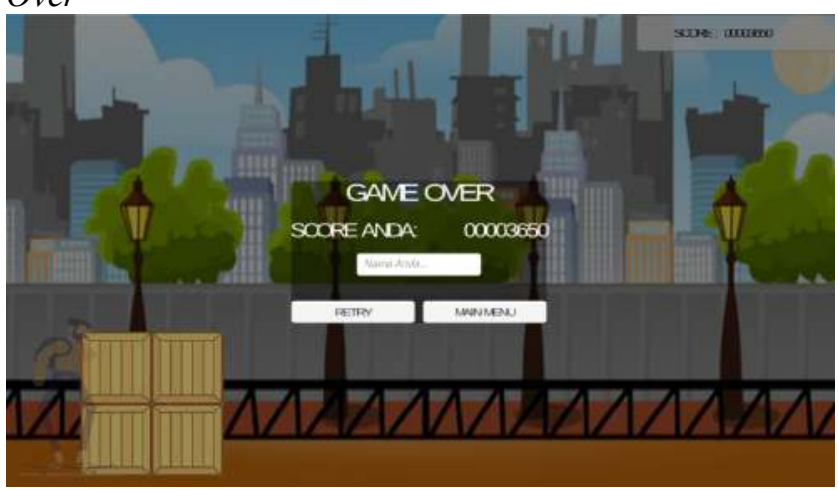

Gambar 4 Halaman Game Over 
Halaman ini merupakan halaman yang menunjukan permainan sudah berakhirkarena player sudah gagal melewati rintangan. Setelah itumenuliskan nama untuk menandai score yang diperoleh. retry untuk bermain lagi, main menu untuk kembali ke menu utama.

4. Halaman High Score

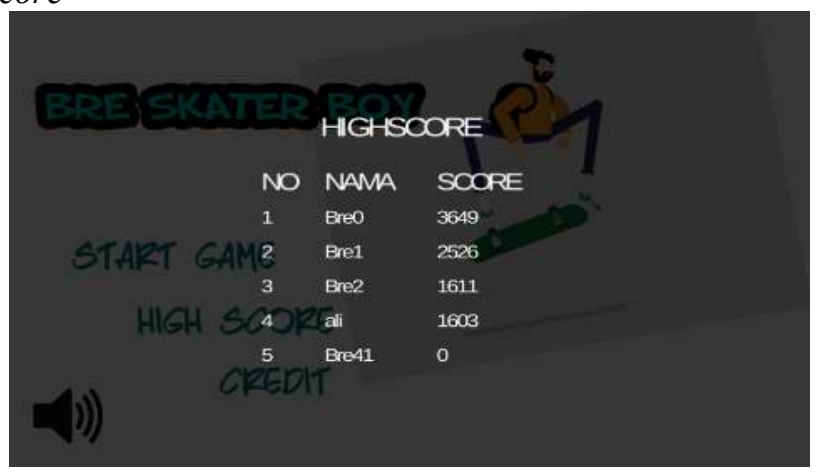

Gambar 5 Halaman High Score

Halaman high score adalah halaman yang berisi tentang score paling tertinggi sampai score paling terendah. Player memperoleh score setelah memainkan satu permainan sampai game over. Jumlah score dihitung dari jauhnya jarak yang telah dilalui oleh playertersebut, serta lamanya waktu permainan yang dimainkan.

5. Halaman Credit

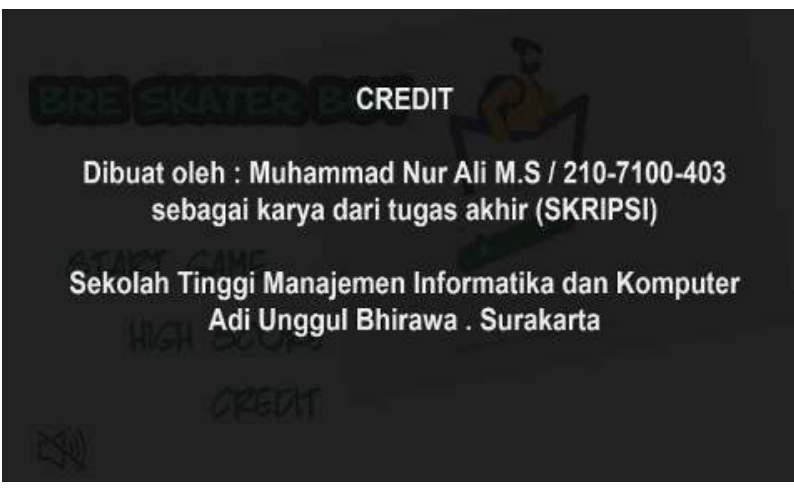

Gambar 6 Halaman Credit

Halaman credit adalah halaman yang berisi info tentang penulis atau perancang Aplikasi Game $2 D$ Petualangan Bre Skater BoyBerbasis Android dan alasan dibuatnya aplikasi game ini.

3.2 Pembahasan Analisis SWOT

Analisis SWOT adalah metode perancangan strategis yang digunakan untuk mengevaluasi kekuatan (strength), kelemahan (weaknesses), peluang (opportunities), dan ancaman (threats) dalam suatu proyek atau suatu spekulasi bisnis. Proses ini melibatkan penentuan tujuan yang spesifik dari sistem dan mengidentifikasi faktor internal dan eksternal yang mendukung maupun yang tidak dalam mencapai tujuan tersebut.

1. Strength (Kekuatan)

Sebagai kekuatan dari aplikasi game ini yang diunggulkan. Antara lain yaitu Game "Bre

Skater Boy" mudah dalam pengoperasian permainanya. Jadi semua kalangan dengan mudah langsung mengoprasikanya. Dan mendidik anak yang memainkan (educative)

2. WeaknessesI (Kelemahan)

Sebagai kelemahan dari aplikasi game ini yaitu hanya dapat dimainkan single player.

3. Opportunities(Peluang)

Sebagai Peluang yang bisa dimanfaatkan oleh penulis dan developer

a. Semakin banyaknya pengguna smartphone android dikalangan masyarakat.

b. Banyak peminat game berbasis android.

4. Threat(Ancaman) 
Sebagai ancaman yang berarti bisa merugikan developer dan juga perancang. Banyaknya game yang sejenis dengan grafis dan fitur yang lebih menarik dapat menjadikan banyak persaingan.

\section{KESIMPULAN}

Dari hasil pembuatan dan pengujian Aplikasi Game 2D Petualangan Bre Skater Boy berbasis Android, dapat ditarik kesimpulan sebagai berikut: telah dibuat Aplikasi Game 2D Petualangan Bre Skater Boy Berbasis Android dengan Game Engine Unity. Aplikasi Game 2D Petualangan Bre Skater Boy Berbasis Android dengan genreendless run adventure dimainkan single player. Player dalam apliakasi game ini berjalan secara otomatis (autorun) melintasi jalan sejauh mungkin dan melewati obstacle (rintangan) dengan melompat disertai dengan flip style (memutarkan papan skate di udara) untuk medapatkan score sebanyak-banyaknya.

\section{SARAN}

Berdasarkan kesimpulan, maka saran yang dapat penulis berikan agar aplikasi dapat dikembangkan menjadi lebih baik adalah sebagai berikut: Ditambahkan animasi gerakan pada karakter Bre Skater Boy agar lebih banyak gerakan dan lebih menarik di dalam game. Menambahkan obyek-obyek animasi pada obstacle (rintangan) yang lebih menarik di dalam game. Dapat dikembangkan dalam game 3D lebih lanjut.

\section{DAFTAR PUSTAKA}

[1] Greenslade, A., 2006. Gamespeak: A glossary of Gaming Terms [online] Tersedia di http://wayback.archive.org/web/20070219082328/http://www.spe cusphere.com/joomla/index.php?option=com_content\&task=view\&id=232\&Itemid=32

[2] Hunicke, R., LeBlanc, M., \& Zubek, R., 2001.MDA: A Formal Approach to Game Design and Game Research. Northwestern University. Tersedia di www.cs.northwestern.edu/ hunicke/MDA.pdf

[3] Jones, Brett. 2015. What is projection mapping? [online] Tersedia di http://projectionmapping.org/whatis/

[4] Jones, B., Shodi, R., Murdock, M., Mehra, R., Hrvoje, B., Wilson, Andrew D., Ofek, E., MacIntyre, B., Raghuvanshi N., \& Shapira, L., 2014. RoomAlive Magical Experiences Enabled by Scalable, Adaptive Projector-Camera Units. Microsoft Research [online]. Tersedia melalui: http://dl.acm.org/ citation.cfm?id=2647383

[5] Levy, L., \& Noak, J., 2010. Game Development Essentials Game QA \& Testing. New York: Delmar, Cengage Learning.

[6] Rogers, S., 2010. Level Up! The Guide to Great Video Game Design. Chicester: John Wiley \& Sons Ltd.

[7] Roy, S., 2016, How to Perform White Box Testing - Explained With a Simple Example. [online]. Tersedia melalui: http://www.softwaretestinghelp.com/white-box-testingtechniques-with-example/

[8] Schell, J., 2015. The Art of Game Design - A Book of Lenses. 2nd edition. Boca Raton: Taylor \& Francis Group.

GO INFOTECH: JURNAL ILMIAH STMIK AUB Vol. 25, No. 1, Juni 2019 : 29 - 34 